\title{
TRACE ELEMENT ANALYSIS OF DIAMOND BY LAM ICPMS: PRELIMINARY RESULTS
}

\author{
Sonal Rege ${ }^{1}$, Rondi M. Davies ${ }^{1,2}$, W.L. Griffin ${ }^{1,3}$, Simon Jackson ${ }^{1}$, \\ Suzanne Y. O'Reilly ${ }^{1}$ \\ 'ARC National Key Centre for Geochemical Evolution and Metallogeny of Continents (GEMOC), Macquarie University, \\ NSW, Australia: ${ }^{2}$. Department of Earth and Planetary Sciences, American Museum of Natural History, \\ New York, USA; ${ }^{3}$. CSIRO Exploration and Mining, P.O. North Ryde, NSW, Australia
}

Mantle-derived diamonds provide valuable insights into mantle processes at high temperatures and pressures. During crystallisation, diamonds commonly include small silicate, oxide and sulfide inclusions and incorporate minor and trace elements such as nitrogen and boron in their crystal lattice. The study of these inclusions can yield information about the chemical, isotopic and mineralogical composition of the host rocks and nature of the fluids from which the diamonds were formed

The trace element composition of diamond may provide information on the conditions and environment of diamond crystallisation. Characterisation of these patterns also may prove useful in recognising diamonds from different sources. We have analysed 115 diamonds for trace elements using a $266 \mathrm{~nm}$ laser microprobe, attached to an Agilent 7500 ICPMS. The diamonds come from a range of localities including Siberia, Eastern Australia (Wellington and Bingara), Brazil (Juina), Canada (Slave) and Thailand. We also have analysed fibrous diamonds from Jwaneng (Botswana) and Central Africa. The study includes both gem-quality and industrial-quality stones; the latter have higher trace element contents.

Analyses were performed in two stages; (1) using a trace element-doped oil as external standard and carbon as the internal standard to measure $\mathrm{Mg}, \mathrm{Al}, \mathrm{Ca}$ and other trace elements; (2) using $\mathrm{Mg}, \mathrm{Al}$ or $\mathrm{Ca}$ as the internal standard to determine other elements with the NIST 612 glass as the external standard.

Based on their syngenetic mineral inclusions, diamonds can be grouped into two main associations, the peridotitic suite, consisting of olivine, ortho-pyroxene, clino-pyroxene and pyrope garnet, and the eclogitic suite, which includes omphacitic clino-pyroxene, garnet, rutile etc. (Meyer, 1987). Superdeep diamonds are characterised by ultra high-pressure phases such as ferropericlase and perovskite (Kaminsky et al, 2001). Mineral inclusions were used to classify the diamonds into eclogitic, peridotitic, superdeep parageneses. The diamonds from Eastern Australia were further classified into Group A and Group B based on their morphological features, mineral inclusions, carbon isotope signatures, nitrogen content and aggregation state and internal structure (Davies et al, 2002).

The analyses of the fibrous diamonds have been used as a basis against which the other diamonds are compared. Unlike most diamonds, these stones have grown very rapidly in the kimberlite magma itself, during its ascent to the surface, and their fibrous structure has trapped samples of the growth medium. These micro-inclusions represent syngenetic mantle fluids under high pressure (e.g. Navon et al., 1988; Navon, 1991).

The trace elements in the fibrous diamonds such as $\mathrm{K}$, $\mathrm{Na}, \mathrm{Rb}, \mathrm{Sr}, \mathrm{Zr}, \mathrm{Cs}, \mathrm{Ba}, \mathrm{Hf}, \mathrm{Ta}, \mathrm{Th}, \mathrm{U}$ and the LREE elements exhibit a wide range in concentrations. This depends on the concentration and distribution of the micro-inclusions between the fibres of the diamond.

The range of concentrations obtained for the JWA 115 diamond from Botswana (Table 1), compares well with

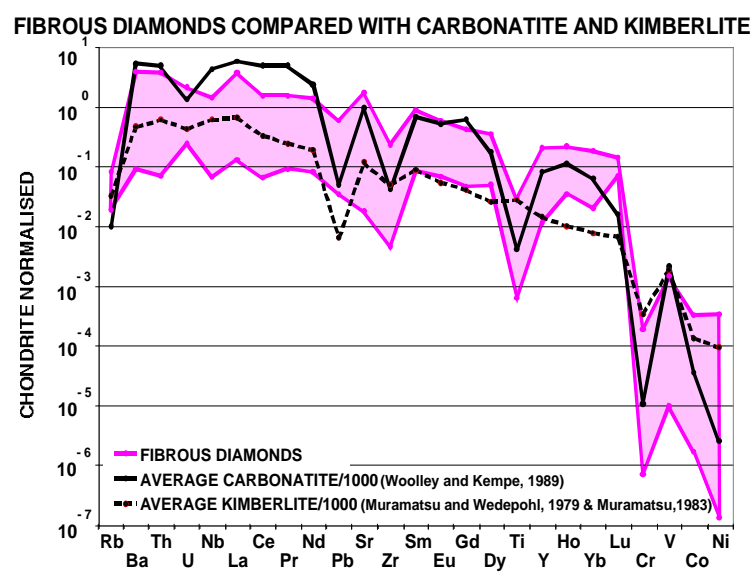

Figure 1: Trace element patterns in fibrous diamonds compared with those in carbonatite and kimberlite 
the NAA analyses of Schrauder et al. (1996), and illustrate the heterogeneity of such fibrous stones.

The fibrous diamonds all have very similar chondritenormalised trace element patterns with moderate LREE enrichment. No Eu anomaly is observed but $\mathrm{Zr}, \mathrm{Ti}, \mathrm{Pb}$ and $\mathrm{Nb}$ show pronounced negative anomalies. This pattern strongly resembles those of average carbonatite and average kimberlite but the strong negative HFSE anomalies are more similar to the carbonatite pattern.

\section{Table 1. Diamond Trace Elements}

\begin{tabular}{|c|c|c|c|c|c|}
\hline \multirow{2}{*}{$\begin{array}{l}\text { ppm } \\
\text { Ti }\end{array}$} & \multicolumn{2}{|c|}{ Minimun Maximum } & \multicolumn{3}{|c|}{$\begin{array}{l}\text { Schrauder } \\
\text { et al., } 1996 \\
\text { MinimunMaximu }\end{array}$} \\
\hline & 6.36 & 12.5 & 9.24 & - & - \\
\hline $\mathbf{R b}$ & 0.054 & 0.183 & 0.119 & 0.403 & 0.587 \\
\hline $\mathbf{S r}$ & 1.48 & 12.1 & 5.30 & 1.95 & 2.40 \\
\hline Y & 0.053 & 0.321 & 0.151 & 0.000 & 0.000 \\
\hline $\mathbf{Z r}$ & 0.140 & 0.336 & 0.241 & 0.420 & 0.503 \\
\hline $\mathbf{N b}$ & 0.061 & 0.129 & 0.096 & - & - \\
\hline $\mathbf{B a}$ & 1.63 & 8.28 & 3.63 & 1.902 & 3.712 \\
\hline $\mathbf{L a}$ & 0.115 & 0.764 & 0.391 & 0.133 & 0.238 \\
\hline $\mathrm{Ce}$ & 0.171 & 0.913 & 0.444 & 0.223 & 0.403 \\
\hline Pr & 0.019 & 0.140 & 0.065 & - & - \\
\hline Nd & 0.081 & 0.623 & 0.300 & - & - \\
\hline $\mathrm{Sm}$ & 0.014 & 0.131 & 0.049 & 0.016 & 0.029 \\
\hline $\mathbf{E u}$ & 0.004 & 0.032 & 0.014 & 0.007 & 0.011 \\
\hline Gd & 0.009 & 0.076 & 0.034 & 0.010 & 0.020 \\
\hline Dy & 0.012 & 0.085 & 0.035 & - & - \\
\hline Ho & 0.002 & 0.012 & 0.005 & - & - \\
\hline $\mathbf{Y b}$ & 0.003 & 0.014 & 0.009 & 0.003 & 0.005 \\
\hline $\mathbf{L u}$ & 0.003 & 0.003 & 0.003 & 0.000 & 0.001 \\
\hline $\mathbf{P b}$ & 0.085 & 0.108 & 0.097 & 0.000 & 0.000 \\
\hline Th & 0.019 & 0.095 & 0.042 & 0.018 & 0.036 \\
\hline $\mathbf{U}$ & 0.002 & 0.015 & 0.006 & 0.010 & 0.010 \\
\hline
\end{tabular}

The superdeep diamonds show negative anomalies in $\mathrm{Zr}, \mathrm{Nb}$ and $\mathrm{Ti}$ and have the negative $\mathrm{Pb}$ anomaly seen in the fibrous diamonds. The diamonds from Juina show more enrichment in the LREE than the Slave superdeep diamonds, which have a flatter pattern moresimilar to that of the fibrous diamonds. The Juina diamonds show a negative $\mathrm{Eu}$ anomaly whereas the Slave diamonds show a positive one. The Slave diamonds also show strong positive $\mathrm{Sr}$ and $\mathrm{Y}$ anomalies.

Peridotitic diamonds worldwide show REE patterns that are generally flatter than that of the fibrous diamonds and have no $\mathrm{Eu}$ anomaly. They also are depleted in $\mathrm{Ni}$ and Co relative to the fibrous diamonds. The greatest relative LREE enrichment is seen in diamonds from Thailand and Dalnaya (Siberia). HFSE anomalies are widely variable. The Slave diamonds show a positive $\mathrm{Nb}$ anomaly and negative $\mathrm{Zr}$ and $\mathrm{Y}$ anomalies whereas diamonds from Wellington and Thailand show a negative $\mathrm{Nb}$ anomaly. Slave, Zarnitsa (Siberia) and Wellington diamonds show negative $\mathrm{Sr}$ anomalies.

The eclogitic diamonds show a range in REE patterns. Although most patterns are relatively flat, the diamonds from Wellington are LREE enriched and have a small negative $\mathrm{Eu}$ anomaly. Diamonds from the Bingara locality have a similar REE pattern, but lack a Eu anomaly and their HFSE anomalies are much deeper than in Wellington diamonds. Slave diamonds show negative $\mathrm{Sr}, \mathrm{Y}, \mathrm{Ti}, \mathrm{Zr}$ and $\mathrm{Nb}$ anomalies.

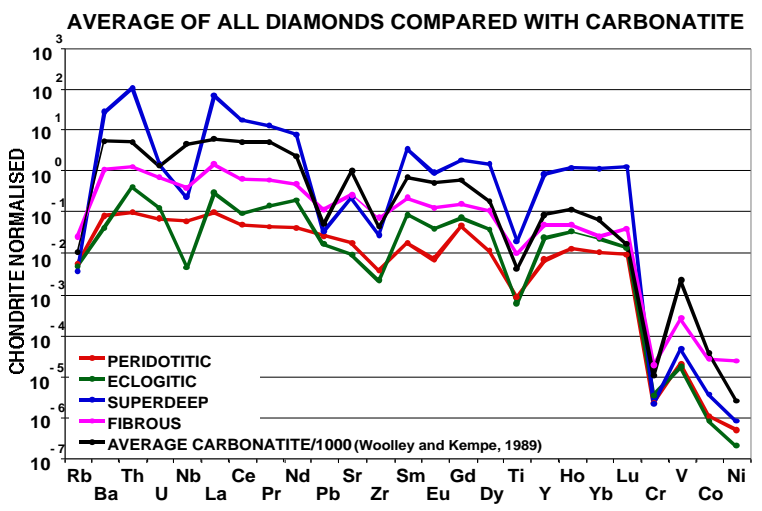

Figure 2: Trace elements in all diamonds compared with those from carbonatite.

The broad similarities in trace element patterns in samples analysed thus far suggest a genetic relationship to carbonatite-like fluids. However, there appear to be some consistent differences between diamonds of different paragenesis, and between diamonds of similar paragenesis from different localities. A larger body of data is required to test these conclusions and further analyses are underway.

\section{REFERENCES}

Davies, R. M., O'Reilly, S.Y and Griffin, W.L. 2002. Multiple Origins of Alluvial Diamonds from New South Wales, Australia." Economic Geology 97, 109-123.

Kaminsky, F. V., Zakharchenko, O.D., Davies, R.M., Griffin, W.L., Kharchatryan-Blinova and Shiryaev, A.A. 2001. Superdeep diamonds from the Juina area, Mato Grosso 
State, Brazil. Contributions to Mineralogy and Petrology 140, 734-753.

Meyer, H. 1987. Inclusions in diamond. In P. Nixon (edit.) Mantle xenoliths. J Wiley \& Sons, Chichester, pp. 501-522.

Muramatsu, Y. 1983. Geochemical investigations of kimberlites from the Kimberley area, South Africa. Geochem. Jour 17, 71 - 86.

Navon, O., Hutcheon, I.D., Rossman, G.R. and Wasserburg, G.J. 1988. Mantle-Derived Fluids in Diamond MicroInclusions. Nature 335, 784-789.

Navon, O. 1991. High Internal-Pressures in Diamond Fluid Inclusions Determined By Infrared-Absorption. Nature 353, 746-748.

Schrauder, M., Koeberl, C. and Navon, O. 1996. Trace element analyses of fluid-bearing diamonds from Jwaneng, Botswana. Geochimica et Cosmochimica Acta 60, 4711-4724.

Wedepohl, K. H. and Y. Muramatsu 1979. The chemical composition of kimberlites compared with the average compositions of three basaltic magma types. SIKC 1 , 300- 312.

Woolley, A. R. and D. R. C. Kempe 1989. Carbonatites: Nomenclature, average chemical compositions and element distribution. In K. Bell (edit.) Carbonatites: Genesis and Evolution. Pp 1-14.

Contact: Sonal Rege, GEMOC ARC National Key Centre, Department of Earth and Planetary Sciences, Macquarie University, NSW, 2109, Australia. email: sreg@laurel.ocs.mq.edu.au: www.es.mq.edu.au/GEMOC/ 